Invited commentary

\title{
ABDOMINAL PAIN IN CHILDREN: LOOK BEYOND THE DIAPHRAGM!
}

\author{
Roberto COPETTI
}

\author{
Emergency Department Latisana \\ General Hospital Latisana, Italy \\ Correspondence: \\ robcopet@gmail.com \\ Tel.: + 390431529328 \\ Fax.: + 390431529461
}

Received: 1 August 2016

Accepted: 5 August 2016

Key words: Lung ultrasound - Abdominal ultrasound - Abdominal pain.

In this retrospective study, Lovrenski et al. (1) investigated the frequency of positive findings within the lung bases during abdominal ultrasound examinations in children with referral diagnosis not suggesting pulmonary disease. The authors reported that with a trans-abdominal (trans-hepatic and transsplenic) approach to both lung bases, pneumonia or pleuropneumonia was detected in 22 patients among 1469 (1257 outpatients and 212 inpatients) being evaluated for abdominal pain of unknown origin. In this study $1.5 \%$ of children with pleuropulmonary disease manifested abdominal pain in absence of respiratory signs. Pneumonia is known as a cause of abdominal pain, especially in cases of paediatric patients. When it occurs, it reveals to be an important symptom because it focuses our attention on the digestive tract, thereby tending to cause diagnostic errors.

This fact had not escaped the keen observation of our forefathers in clinical medicine.
In 1902 Maurice Richardson described a series of clinical cases regarding patients with acute intrathoracic diseases with clinical presentation suggesting acute appendicitis (2). He wrote: "That there should be any difficulty in discriminating between acute thoracic and acute abdominal lesions seems, on the face of it, absurd; yet in an experience of between two and three thousand cases of acute abdominal disease the question has arisen often enough to make a deep impression upon me". In the same year H.L Barnard published a paper entitled:" The simulation of acute peritonitis by pleuro-pneumonic diseases" (3). In 1903 James B. Herrick published a very interesting paper entitled "Abdominal pain in pleurisy and pneumonia" in which he explains, in an admirable way, the reason for this phenomenon (4).

The originality of Lovrenski's and his colleagues paper does not certainly consist in having reproposed a topic known since the dawn of modern medicine. Lovrenski's study is interesting because it stimulates several considerations. First of all the authors reaffirm the important diagnostic role of lung ultrasound. Despite the scientific evidences produced in the last 15 years, lung ultrasound is not widely used as it should be. At present, lung ultrasound is not included in the guidelines on best known practices for diagnosing pneumonia or other pulmonary diseases. Lung ultrasound can be adopted as a simple and noninvasive tool for evaluating children with various respiratory problems. 
It is easy to perform at the patient's bedside, it allows close follow-up and avoids the use of ionising radiation. The problem of ionising radiation is an ethical problem especially in children and newborns in which serious concerns about radiation exposure have been raised. It is curious to note that the greatest resistance to the spread of lung ultrasound has arisen particularly in radiological areas (5). Certainly Lovrenski is a radiologist who is not afraid of novelty.

The trans-abdominal, trans-hepatic and trans-splenic, approach to both lung bases during abdominal ultrasound suggested by Lovrenski and colleagues is very interesting. Its practical implications in the evaluation of abdominal pain of unknown origin are obvious and well described in this paper. The results of this study suggest that children with abdominal pain should also undergo a transthoracic evaluation of the lungs when no abdominal pathology is detected and trans-abdominal evaluation of lung bases is normal. In fact, not only basal pneumonia may occur with abdominal pain.

Current indications on lung ultrasound execution (6) do not include the trans-abdominal approach that Lovrenski and colleagues show to be instead extremely useful. In a patient the authors found pneumonia only with trans-abdominal approach while trans-thoracic examination was completely negative.

\section{Conclusion}

As in previous studies (7) Lovrenski stresses the clinical role of ultrasound considering ultrasound not only as anatomical assessment instrument but also as a useful tool for understanding the clinical manifestations. Diagnoses are the comprehension of clinical presentations, signs and symptoms. Lovrenski and colleagues find pleuropulmonary disease in $1.5 \%$ of children with abdominal pain because they know how to look beyond the diaphragm. This is what I call the clinical ultrasound: which means to use ultrasound as a stethoscope, the best stethoscope that you can have today.

Conflict of interest: The author declares that he has no conflict of interest.

\section{References}

1. Lovrenski J, Popadic D, Varga I, Petrovic S. Abdominal ultrasound in children - Are we careful enough when it comes to lung bases? Paediatrics today. 2016;12(1):139-48.

2. Richardson M. Papers on the Diagnosis of Appendicitis. Boston Med Surg J. 1902;146:399-403.

3. Barnard H.L, M.S. Lond., F.R.C.S. Eng. The simulation of acute peritonitis by pleuro-pneumonic diseases. The Lancet. 1902;160:280-3.

4. Herrick JB. Abdominal pain in pleurisy and pneumonia. JAMA. 1903;XLI(9):535-40.

5. Tomà $\mathrm{P}$, Owens CM. Chest ultrasound in children: critical appraisal. Pediatr Radiol. 2013;43(11):1427-34.

6. Volpicelli G, Elbarbary M, Blaivas M, Lichtenstein DA, Mathis G, Kirkpatrick AW, et al; International Liaison Committee on Lung Ultrasound (ILC-LUS) for International Consensus Conference on Lung Ultrasound (ICC-LUS). International evidence-based recommendations for pointof-care lung ultrasound. Intensive Care Med. 2012;38(4):577-91.

7. Lovrenski J, Petrović S, Balj-Barbir S, Jokić R, Vilotijević-Dautović G. Stethoscope vs. ultrasound probe - which is more reliable in children with suspected pneumonia? Acta Med Acad. 2016;45(1):39-50. 